\title{
Involvement of the Interferon Signaling Pathways in Pancreatic Cancer Cells
}

\author{
MARIKO FUJISAWA ${ }^{1}$, TATSUO KANDA ${ }^{1}$, TOSHIKATSU SHIBATA $^{1}$, REINA SASAKI ${ }^{1}$, RYOTA MASUZAKI $^{1}$, \\ NAOKI MATSUMOTO ${ }^{1}$, KAZUSHIGE NIREI ${ }^{1}$, HIROO IMAZU ${ }^{1}$, KAZUMICHI KURODA ${ }^{1}$, \\ MASAHIKO SUGITANI ${ }^{2}$, TADATOSHI TAKAYAMA ${ }^{3}$ and MITSUHIKO MORIYAMA ${ }^{1}$ \\ ${ }^{1}$ Division of Gastroenterology and Hepatology, Department of Medicine, \\ Nihon University School of Medicine, Tokyo, Japan; \\ ${ }^{2}$ Department of Pathology, Nihon University School of Medicine, Tokyo, Japan; \\ ${ }^{3}$ Department of Digestive Surgery, Nihon University School of Medicine, Tokyo, Japan
}

\begin{abstract}
Background/Aim: To examine interferon (IFN) signaling pathways in human pancreatic cancer cells and their therapeutic application for pancreatic ductal adenocarcinoma (PDAC). Materials and Methods: We examined the effects of IFNa on cytotoxicity, migration, as well as on the levels of tolllike receptor (TLR) signaling pathway-associated genes expression in pancreatic cancer cells. We also examined the additive effects of IFN $\alpha$ and poly $(I-C)$ on tyrosine kinase inhibitor (TKI)-induced cytotoxicity. We performed transcriptome analysis (RNA-Seq) of clinical samples and compared the profile between pancreatic intraepithelial neoplasias (PanINs) and PDACs. Results: IFNa suppressed cell viability and cell migration, and affected TLR signaling pathways, in pancreatic cancer cells. TLR3 is one of the potential genes involved in IFNtreated pancreatic cancer cells. Furthermore, similar to IFN, extracellular addition of poly $(I-C)$ enhanced TKI-induced cytotoxicity in pancreatic cancer cells. RNA-Seq analysis demonstrated that IFN signaling is one of the potential pathways involved in the progression of PanIN to PDAC. Conclusion: IFN signaling may be involved in the development of PDAC. Treatments that target the IFN and TLR3 signaling pathways may be therapeutic options against PDAC.
\end{abstract}

The worldwide annual new cases of and deaths due to pancreatic ductal adenocarcinoma (PDAC) are estimated to

This article is freely accessible online.

Correspondence to: Tatsuo Kanda, MD, Ph.D., Associate Professor, Division of Gastroenterology and Hepatology, Department of Medicine, Nihon University School of Medicine, 30-1 Oyaguchikamicho, Itabashi-ku, Tokyo 173-8610, Japan. Tel: +81 339728111, Fax: + 81 339568496, e-mail: kanda.tatsuo@nihon-u.ac.jp

Key Words: Interferon, pancreatic cancer, RNA-Seq, TKI, Toll-like receptor. be at 458,918 and 432,242, respectively (1). Most patients with PDAC remain asymptomatic until the disease reaches an advanced stage (2). Despite the development of treatment methods, PDAC is still associated with a poor prognosis and a high case-fatality rate. Unfortunately, a specific diagnostic biomarker for the detection of early stage PDAC has not yet been developed (3).

Currently, it is well known that smoking, obesity, dietary factors (such as having a non-vegetarian diet), toxins, and excess alcohol intake are modifiable risk factors for PDAC. Additionally, aging, familial cancer syndromes, AfricanAmerican race, a history of chronic pancreatitis, diabetes mellitus, and a non-O blood group are non-modifiable risk factors for PDAC (4). Further investigations of the pathogenesis and mechanism of PDAC are needed (5).

Immunotherapeutic approaches for PDAC may involve not only the stimulation of the immune system but also the precise control of tumor immunosuppressive effects through tumor microenvironments in PDAC patients (6-8). Type I interferons (IFNs), such as IFN $\alpha$ and IFN $\beta$, exert their effects via the type I IFN receptor, which results in the activation of the Janus kinases Jak1 and Tyk2, the phosphorylation and activation of the latent cytoplasmic signal transducers and activators of transcription (STAT1 and STAT2), the formation of a transcription complex in conjunction with IFN regulatory factor 9 (IRF9), and the activation of IFN-stimulated genes (ISGs) that are responsible for mediating the biological activities of type I IFNs (9). Thus, IFNs also affect innate immune signaling pathways.

Booy et al. reported that $91.5 \%$ of pancreatic cancers exhibited IFN $\alpha$ receptor- 1 expression, and $23.4 \%$ of these cancers were strongly positive. Furthermore, $68.1 \%$ of the pancreatic cancers exhibited IFN $\alpha$ receptor-2c expression and $4.3 \%$ of these cancers exhibited strong expression as indicated by immunohistochemistry of the paraffinembedded pancreatic cancer tissues (10). 
IFN $\alpha$ has potential antitumor effects on solid organ cancers (including PDAC), although the only randomized clinical trial focusing on the treatment of patients with pancreatic cancer did not demonstrate a significant increase in overall survival (11-15). However, it is not well known whether IFN has antitumor activities in PDAC and inhibitory effects on the pathogenesis of PDAC.

The innate immune response produces type I IFN and elicits apoptosis in susceptible cells, including pancreatic cancer cells (16). Constitutive toll-like receptor 3 (TLR3) expression is associated with constitutive Wingless (Wnt) family member 5A (Wnt5A) expression in PDAC (17). Phenylmethimazole (C10), which is a small TLR signaling inhibitor, has been observed to decrease constitutive Wnt5A and TLR3 expression levels together with the inhibition of cell growth and migration both in vivo and in vitro (17). In contrast, TLR3 and TLR7 agonists [poly(I-C) and imiquimod, respectively] enhance PDAC cell lysis via human gammadelta T cells (18).

Noninvasive precursors of invasive PDAC include pancreatic intraepithelial neoplasias (PanINs), intraductal papillary mucinous neoplasms (IPMNs), and mucinous cystic neoplasms (19). Low-grade PanINs (PanIN-1) are common with increasing age and high-grade PanINs (PanIN-3) are usually present in pancreas with invasive cancer. Although PanINs can harbor the somatic genetic alterations seen in invasive pancreatic cancers, the differences in gene expression between PanIN and PDAC are not well known (20).

In the present study, we investigated the TLR signaling pathway following IFN $\alpha$ treatment of pancreatic cancer cell lines. We observed that IFN $\alpha$ up-regulated TLR3 mRNA expression in human pancreatic cancer cell lines. We demonstrated that IFN $\alpha$ and poly(I-C) enhanced the cytotoxicity induced by tyrosine kinase inhibitors (TKIs) in human pancreatic cancer cell lines. We also examined the difference of PDACs and intermediate-grade PanINs (PanIN-2) using laser microdissection (LMD) and transcriptome analysis (RNA-Seq). Our results demonstrate that IFN signaling pathways may be involved in the development of PDAC and that modulation of the IFN and TLR signaling pathways may be a new therapeutic option for the treatment of PDAC.

\section{Materials and Methods}

Patients and clinical specimens. The present study included 5 patients with PDAC who underwent surgical treatment at the Department of Digestive Surgery, Nihon University School of Medicine between May 2016 and December 2017. The study protocol was approved by the Ethics Committee of Nihon University School of Medicine (241-1) and conformed to the ethical guidelines of the Declaration of Helsinki. Written informed consent was obtained from all patients. All pancreas tissues in the present study had cancerous lesion, pancreatic intraepithelial neoplasia (PanIN), and background non-cancerous parts (pancreatic ductal epithelial cells) which were pathologically diagnosed by three authors (MF, MS and MM), according to the WHO Classification of Tumors of the Digestive System (21).

Laser microdissection (LMD). Formalin-fixed paraffin-embedded (FFPE) tissue samples were cut into $5 \mu \mathrm{m}$ sections and mounted on slides covered with polyethylene-naphthalate-membrane (Leica, Wetzler, Hessen, Germany) for LMD. After deparaffinization performed directly on the slides, the slides were stained with hematoxylin and eosin (HE). By the LMD method that was conducted using LMD6000 (Leica), target lesions (pancreatic ductal epithelial cells, PanIN and PDAC) were dissected and directly conformed to RNA extraction. The total cut-out area was summed to more than $300,000 \mu \mathrm{m}^{2}$.

RNA extraction and RNA-Seq by next generation sequencing. RNA extraction of FFPE samples was performed using RNeasy FFPE Kit (Qiagen, Hilden, Germany), according to the manufacturer's instructions. RNA quantity and quality were assessed by NanoDrop ND-1000 spectrophotometer (Thermo Scientific, Waltham, MA, USA) and the 2100 Bioanalyzer (Agilent, Santa Clara, CA, USA).

According to Illumina platform, each cDNA library was constructed by TruSeqTM RNA Exome Kit (Illumina, San Diego, CA, USA). One hundred and fifty bp paired-end sequencing protocol providing approximately 15 gigabases per sample was performed on Illumina HiSeq X10 (Illumina) with using Illumina NovaSeq reagent kit. Raw data obtained from sequencing was processed by filtering of index adapter sequences and low-quality reads. These RNA-Seq and data processing were outsourced to BGI Hong Kong Tech Solution GS Lab (BGI, Hong Kong, PR China). The analysis of potential target genes was carried out using Ingenuity pathways analysis (IPA) (Qiagen).

Cell lines and reagents. The human pancreatic cancer cell lines Panc1 and SUIT-2 have been previously described (22) and were grown in Roswell Park Memorial Institute media (RPMI)-1640 (Sigma-Aldrich, St. Louis, MO, USA) supplemented with $10 \%$ fetal bovine serum, 100 $\mathrm{U} / \mathrm{ml}$ penicillin and $100 \mu \mathrm{g}$ streptomycin at $37^{\circ} \mathrm{C}$ under $5 \% \mathrm{CO}_{2}$. IFNa-2a, poly(I-C), sorafenib, and regorafenib were purchased from Sigma-Aldrich, Imgenex (San Diego, CA, USA), AdooQ Bioscience (Irvine, CA, USA) and Cayman Chemical (Ann Arbor, MI, USA), respectively. Small interfering RNA (siRNA) against TLR3 (si-TLR3) [sc-36685] and control siRNA (si-C) [sc-37007] were purchased from Santa Cruz Biotechnology (Santa Cruz, CA, USA).

RNA extraction, cDNA synthesis and PCR array for TLR-associated signaling pathway-associated pathways. Human pancreatic cancer cell lines (Panc-1 or SUIT-2) were treated either with or without 0.1

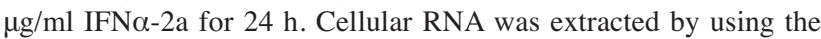
RNeasy Mini kit (Qiagen, Hilden, Germany), and RNA concentration was determined by using a NanoDrop (Thermo Scientific, Tokyo Japan) (23). A RT2 First Strand kit (Qiagen) was used on a GeneAmp PCR system 5700 (Applied Biosystems, Foster, CA, USA) to synthesize cDNA from $1.0 \mu \mathrm{g}$ RNA each for one plate (23).

TLR-associated signaling pathways were analyzed by using a RT2 profiler PCR array, which was performed on a 7500 Fast RealTime PCR System (Applied Biosystems). To normalize the raw data for analysis, we automatically selected an optimal set of reference genes by using automatic selection from the full panel method, according to the manufacturer's instructions (23). 

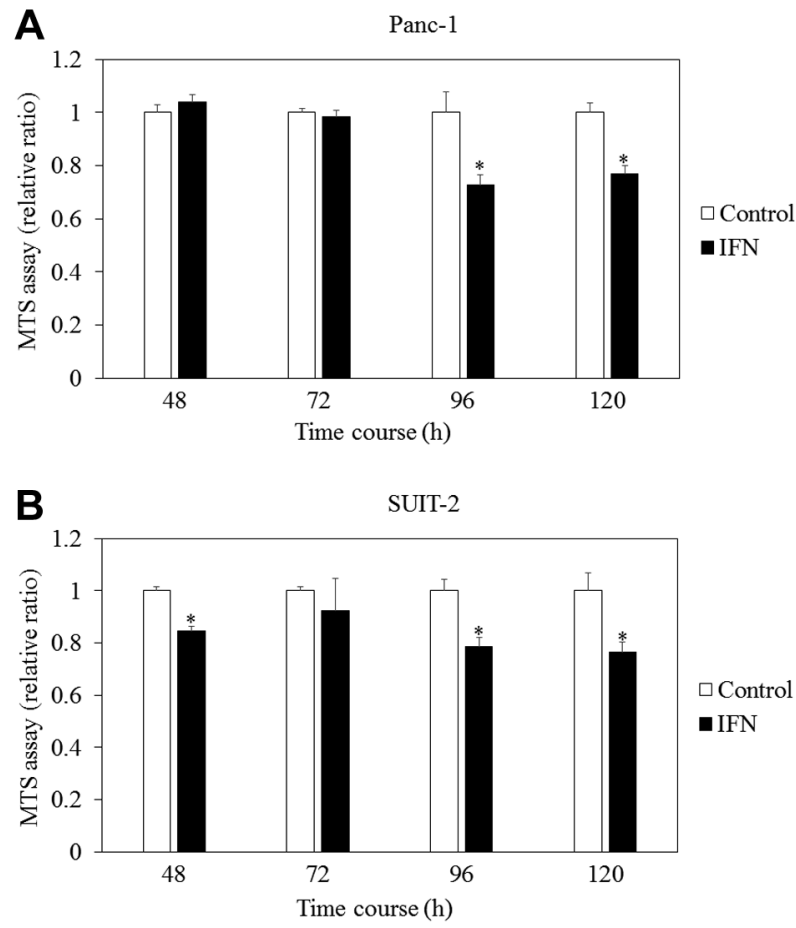

Figure 1. Viability of human pancreatic cancer cell lines treated with or without IFNa. (A) Panc-1, (B) SUIT-2. Cells were treated with 0.05 $\mu \mathrm{g} / \mathrm{ml}$ IFNa for the indicated times. Cell viability was evaluated with MTS assays (Promega, Madison, WI, USA). ${ }^{*} p<0.05$, compared with the untreated control (open bar).

Cell proliferation and cytotoxic assay. To evaluate cell proliferation and viability, dimethylthiazol carboxymethoxyphenyl sulfophenyl tetrazolium (MTS) assays were performed with a CellTiter 96 Aqueous One-Solution cell proliferation kit (Promega, Madison, WI, USA), according to the manufacturer's instructions. For each well, the absorbance at $490 \mathrm{~nm}$ was measured with the iMark Microplate Absorbance Reader (Bio-Rad, Tokyo, Japan) (23).

Wound-healing scratch assay. Cells were grown on 60-mm cell culture dishes until confluence. A p-200 pipette tip was used to scratch the dish, and the serum-free medium either included or did not include the treatment (24). Up to $48 \mathrm{~h}$ after scratching, the cells were observed via microscopy (BIOREVIO BZ-9000, Keyence, Osaka, Japan). The migration activity was presented as a ratio, and the migration in the untreated control was considered to be 1 (24).

Transfection of siRNA. Twenty-four hours before transfection, cells were seeded at $1.5 \times 10^{5}$ cells per well in 6-well plates. Cells were transfected with $50 \mathrm{nM}$ si-TLR3 or si-C using the Effectene transfection reagent (Qiagen, Hilden, Germany), according to the manufacturer's instructions (22). After $48 \mathrm{~h}$ of transfection, cells were treated with IFN $\alpha(0.05 \mu \mathrm{g} / \mathrm{ml})$, either with or without regorafenib $(1 \mu \mathrm{M})$. After $96 \mathrm{~h}$ of transfection, MTS assays were performed to evaluate cell viability.
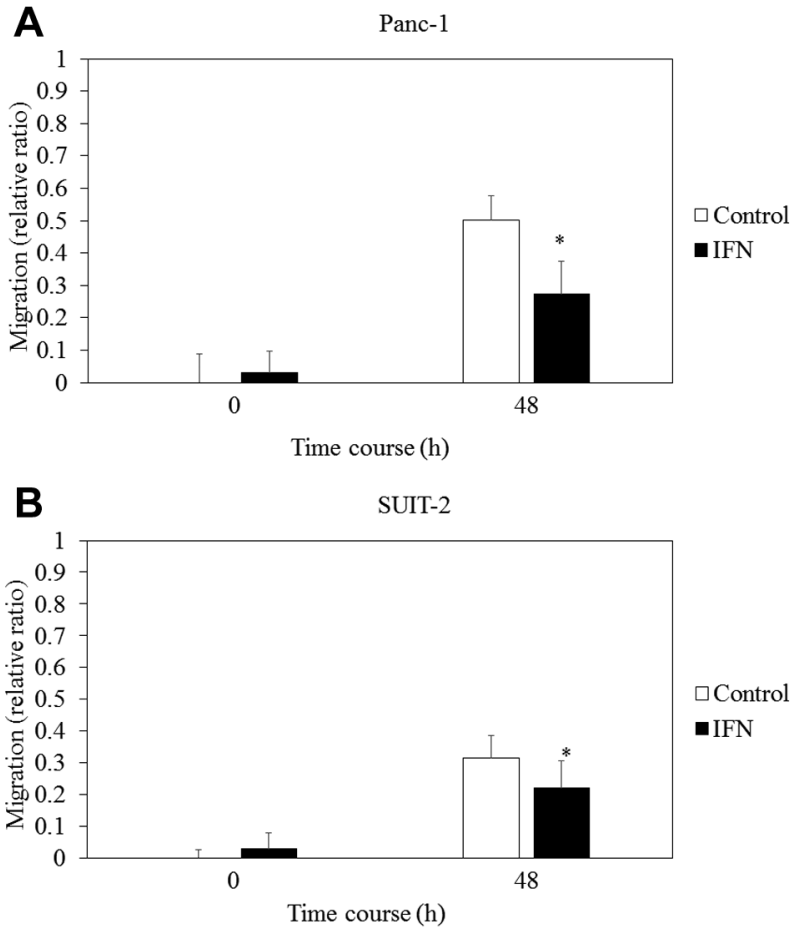

Figure 2. IFN 2 inhibits the migration of pancreatic cancer cell lines. (A) Panc-1, (B) SUIT-2. Wound-healing scratch assays were performed. The observed migration is presented as a ratio of migration, considering the migration in the control at 0 hours as $0.01 .{ }^{*} p<0.05$, compared with the untreated control at $48 \mathrm{~h}$ (open bar).

Statistical analysis. Data are indicated as the mean \pm standard deviation (SD). Statistical analyses were performed by using a 2tailed Student $t$-test or a Chi-square test. All the experiments were independently performed at least three times. Values of $p<0.05$ were considered to indicate a statistically significant difference. Statistical analyses were performed with the DA Stats software version PAF01644 (NIFTY Corp., Tokyo, Japan).

\section{Results}

IFNa inhibits viabiliy of human pancreatic cancer cell lines. In general, IFN has been demonstrated to have antitumor potential against human solid cancers (11-15). PDAC also expresses type I IFN receptors (10). These facts prompted us to investigate the effects of IFN $\alpha$ on the viability of human pancreatic cancer cell lines. As shown in Figure 1, the results of the MTS assay demonstrated that IFN $\alpha$ treatment suppressed the viability of both Panc-1 and SUIT-2 cells, compared with the cells that were treated without IFN $\alpha$.

IFNa inhibits migration of human pancreatic cancer cell lines. We also performed a wound-healing scratch assay in human pancreatic cells that were treated with or without 
Table I. Up-regulation of Toll-like receptor-associated genes by interferon in human pancreatic cell line Panc-1.

\begin{tabular}{lcc}
\hline Genes & Fold regulation & $p$-Value \\
\hline TLR3 & $\mathbf{2 3 . 7 3}$ & $\mathbf{0 . 0 0 0 4 9 6}$ \\
CXCL10 & $\mathbf{6 . 0 4}$ & $\mathbf{0 . 0 0 0 0 8 8}$ \\
MYD88 & $\mathbf{4 . 4 0}$ & $\mathbf{0 . 0 0 0 0 9 1}$ \\
EIF2AK2 & $\mathbf{4 . 3 9}$ & $\mathbf{0 . 0 0 0 2 8 2}$ \\
CSF3 & $\mathbf{3 . 7 6}$ & $\mathbf{0 . 0 0 9 5 0 3}$ \\
IL6 & 3.61 & 0.125579 \\
IRF1 & $\mathbf{3 . 3 8}$ & $\mathbf{0 . 0 1 3 5 8 0}$ \\
IFNB1 & 2.91 & 0.176126 \\
TLR2 & $\mathbf{2 . 4 9}$ & $\mathbf{0 . 0 0 0 9 5 6}$ \\
B2M & $\mathbf{2 . 4 8}$ & $\mathbf{0 . 0 0 0 1 1 7}$ \\
IL12A & $\mathbf{2 . 3 3}$ & $\mathbf{0 . 0 0 0 8 2 9}$ \\
IL1B & $\mathbf{2 . 2 0}$ & $\mathbf{0 . 0 2 0 4 4 6}$ \\
TNF & $\mathbf{2 . 1 5}$ & $\mathbf{0 . 0 0 1 9 4 8}$ \\
\hline
\end{tabular}

TLR3: Toll like receptor 3; CXCL10: C-X-C motif chemokine ligand 10; MYD88: MYD88 innate immune signal transduction adaptor; EIF2AK2: eukaryotic translation initiation factor 2 alpha kinase 2; CSF3: colony stimulating factor 3; IL6: interleukin 6; IFNB1: interferon beta 1; IRF1: interferon regulatory factor 1; TLR2: toll like receptor 2; B2M: beta-2-microglobulin; IL12A: interleukin 12A; IL1B: interleukin 1 beta; TNF: tumor necrosis factor. Bold genes, threshold of fold regulation and $p$-values are 2 and 0.05 , respectively.

Table II. Up-regulation of Toll-like receptor-associated genes by interferon in human pancreatic cell line SUIT-2.

\begin{tabular}{lrc}
\hline Genes & Fold regulation & $p$-Value \\
\hline CXCL10 & $\mathbf{1 0 8 . 5 9}$ & $\mathbf{0 . 0 0 3 3 5 3}$ \\
IFNB1 & 4.17 & 0.143835 \\
MYD88 & $\mathbf{3 . 3 2}$ & $\mathbf{0 . 0 0 2 3 4 9}$ \\
SIGIRR & $\mathbf{3 . 0 9}$ & $\mathbf{0 . 0 0 8 0 3 8}$ \\
TLR3 & $\mathbf{2 . 9 5}$ & $\mathbf{0 . 0 0 3 0 3 9}$ \\
NFKB1A & $\mathbf{2 . 4 1}$ & $\mathbf{0 . 0 3 5 1 1 6}$ \\
EIF2AK2 & 2.03 & 0.199155 \\
\hline
\end{tabular}

SIGIRR: Single Ig and TIR domain containing; NFKB1A: nuclear factor kappa B subunit 1 . Bold genes, threshold of fold regulation and $p$-values are 2 and 0.05 , respectively.

IFN $\alpha$ to examine the effects of IFN $\alpha$ on the migration of these cells. As shown in Figure 2, the results of the woundhealing scratch assay demonstrated that IFN $\alpha$ treatment suppressed migration of both Panc-1 and SUIT-2 cells, compared with the cells that were treated without IFN $\alpha$. Thus, because IFN $\alpha$ inhibited viability and migration of human pancreatic cancer cell lines, IFN signaling pathways seem to be involved in pancreatic carcinogenesis. Therefore, the molecular mechanisms were further examined.

Up-regulation of TLR3, CXCL10, and MYD88 in human pancreatic cancer cell lines treated with IFNa. IdaHosonuma et al. created poliovirus receptor-transgenic mice
Table III. Down-regulation of toll-like receptor-associated genes by interferon in human pancreatic cell line Panc-1.

\begin{tabular}{lcc}
\hline Genes & Fold regulation & $p$-Value \\
\hline CLEC4E & -2.06 & 0.385352 \\
TLR5 & -2.49 & 0.098818 \\
\hline
\end{tabular}

CLEC4E: C-type lectin domain family 4 member E; TLR5: toll-like receptor 5. Bold genes, threshold of fold regulation and $p$-values are 2 and 0.05 , respectively.

Table IV. Down-regulation of toll-like receptor-associated genes by interferon in human pancreatic cell line SUIT-2.

\begin{tabular}{lcc}
\hline Genes & Fold regulation & $p$-Value \\
\hline SARM1 & -2.09 & 0.214029 \\
TICAM2 & -2.10 & 0.064764 \\
MAP3K7 & -2.11 & 0.235700 \\
MAP4K4 & -2.15 & 0.150279 \\
ELK1 & -2.23 & 0.190234 \\
IRAK1 & -2.24 & 0.225715 \\
HSPD1 & -2.43 & 0.332232 \\
RIPK2 & $\mathbf{- 2 . 5 0}$ & $\mathbf{0 . 0 2 8 9 2 1}$ \\
IFNA1 & $\mathbf{- 4 . 6 4}$ & $\mathbf{0 . 0 1 3 9 7 8}$ \\
\hline
\end{tabular}

SARM1: Sterile alpha and TIR motif containing 1; TICAM2: toll like receptor adaptor molecule 2; MAP3K7: mitogen-activated protein kinase 7; MAP4k4: mitogen-activated protein kinase 4; ELK1: ETS transcription factor ELK1; IRAK1: interleukin 1 receptor associated kinase 1; HSPD1: heat shock protein family D (Hsp60) member 1; RIPK2: receptor interacting serine/threonine kinase 2; IFNA1: interferon alpha 1; Bold genes, threshold of fold regulation and $p$-values are 2 and 0.05 , respectively.

that were crossed with IFN $\alpha / \beta$ receptor knockout mice, and they observed very high titers of poliovirus in the pancreatic tissues on day 3 after poliovirus infection, suggesting that the IFN signaling system is also an important pathway in the pancreas (25). Subsequently, we examined the effects of IFNa on innate immunity (including TLR signaling pathways) in human pancreatic cancer cells. We extracted total RNAs from Panc-1 and SUIT- 2 cells that were treated with or without IFN $\alpha$ to examine the influence of IFN $\alpha$ on TLR signaling pathways by using a real-time RT-PCR-based array (Tables I-IV; Figure 3).

Among the 90 genes that were examined, 11 and 5 genes were significantly up-regulated by IFN $\alpha$ in Panc-1 and SUIT- 2 cells, respectively. We observed that IFN $\alpha$ induced the significant up-regulation of TLR3, CXCL10, and MYD88 mRNA in both cell lines (Tables I, II). However, no genes were significantly down-regulated by IFN $\alpha$ in the Panc-1 cells (Table III), although IFNA1 and RIPK2 mRNAs were significantly down-regulated in SUIT-2 cells (Table IV). 
Fujisawa et al: Pancreatic Cancer and Interferon

Table V. Characteristics of patients with pancreatic cancer in the present study.

\begin{tabular}{lcccccc}
\hline Case No. & Age (years)/gender & Site & Size of tumor $(\mathrm{cm})$ & Histological type & Staging & Type of surgery \\
\hline 1 & $77 /$ male & Head & 1 & Tub2 & T3N0M0 & Pancreaticoduodenectomy \\
2 & $72 /$ male & Head & 2 & Tub2 & T2N1M0 & Pancreaticoduodenectomy \\
3 & $64 /$ female & Body & 1 & Tub2 & T1N0M0 & Distal pancreatectomy \\
4 & $77 /$ male & Body & 1 & Tub2 & T1N0M0 & Distal pancreatectomy \\
5 & $50 /$ female & Head & 3 & Tub1 & T3N1M0 & Pancreaticoduodenectomy \\
\hline
\end{tabular}

Tub1: Well differentiated tubular adenocarcinoma; Tub2: moderately differentiated tubular adenocarcinoma.

IFN $\alpha$ enhances the cytotoxicity of TKIs in human pancreatic cancer cell lines. Because limited clinical activity was observed with either of the TKI monotherapies in patients with advanced pancreatic cancer (26), we next examined whether IFN $\alpha$ enhances the cytotoxicity of TKIs in vitro (Figure 4). We confirmed that the combination of TKIs and IFN $\alpha$ significantly enhanced cytotoxicity, compared with monotherapies with either TKIs or IFN $\alpha$, in Panc-1 (Figure 4A) and SUIT-2 cells (Figure 4B).

TLR3 ligand poly(I-C) enhances the cytotoxicity of TKIs in human pancreatic cancer cell lines. We also examined whether the TLR3 ligand poly(I-C) enhances the cytotoxicity of TKIs in vitro (Figure 4). We confirmed that the combination of TKIs and extracellular addition of poly(I-C) significantly enhanced cytotoxicity, compared with those of TKIs or extracellular addition of poly(I-C) in Panc-1 (Figure 4A) and SUIT-2 (Figure 4B). Of interest, there were no differences in the effects between the TKIs/IFN $\alpha$ combination and the TKIs/poly(I-C) combination groups (Figure 4).

Small interfering RNA (siRNA) for TLR3 attenuates the cytotoxicity induced by IFN $\alpha$ and regorafenib in human pancreatic cancer cell lines. In Panc-1 cells, cytotoxicity in the presence of IFN $\alpha$ did not differ between cells that were transfected with si-C $(1.0 \pm 0.019, \mathrm{n}=6)$ and cells that were transfected with si-TRL3 $(1.0 \pm 0.037, \mathrm{n}=6)$. However, the cytotoxicity of IFN $\alpha$ plus regorafenib was attenuated in Panc- 1 cells that were transfected with si-TLR3 (1.0 \pm 0.032 , $\mathrm{n}=6$ ), compared with those cells that were transfected with si-C $(0.89 \pm 0.023, \mathrm{n}=6 ; p<0.05)$.

In SUIT-2 cells, although cytotoxicity in the presence of IFN $\alpha$ was not attenuated in cells that were transfected with siTRL3 (1.1 $\pm 0.027, \mathrm{n}=6)$, compared to cells that were transfected with si-C $(1.0 \pm 0.060, n=6)$, cytotoxicity of IFN $\alpha$ plus regorafenib was attenuated in SUIT-2 cells that were transfected with si-TLR3 $(1.1 \pm 0.042, \mathrm{n}=6)$, compared with cells that were transfected with si-C $(1.0 \pm 0.024, \mathrm{n}=6 ; p<0.05)$.

In the case of the knockdown of endogenous TLR3, cytotoxicity was not changed with the sole administration of IFN $\alpha$. However, the knockdown of endogenous TLR3 attenuated the cytotoxicity induced by the combination of IFN $\alpha$ plus regorafenib.

IPA between PanIN and PDAC from 5 clinical samples showed the importance of IFN signaling pathway. We further performed RNA-Seq in 5 patients with PDAC (Table V), to study the molecular mechanism of the development of PDAC. Of interest, IPA between PanIN and PDAC from 5 clinical samples showed the importance of IFN signaling pathway (Tables VI, VII). Four of the 5 top canonical pathways were associated with immune signaling pathways including IFN and innate immunity-related signaling pathways (Table VI). IFNA2, promyelocytic leukemia (PML), IFN $\alpha$, IFN lambda 1 (IFNL1/IL29) and IRF7 are extracted as 5 top upstream regulators (Table VII). Activation of IFN $\alpha$ receptor-mediated signaling induced the oncogene PDAC up-regulated factor (PAUF) and made PDAC resistant to oncolytic parvovirus $\mathrm{H}-1$ infection (27). Swayden demonstrated an alteration of PML protein sumoylation was associated with both gemcitabine and oxaliplatin resistance in pancreatic cancer MIAPaCa cells (28). TLRs play a role in the induction of the immune response against tumor development. The TLR7 agonist gardiquimod up-regulated expression levels of IFNL1 and matrix metallopeptidase 9 (MMP-9) (29). IFNL1 also exhibits anti-tumor effects in pancreatic cancer Pan-48 cells through the up-regulation of cyclin-dependent kinase inhibitor 1 (p21) and Bcl-2-associated X protein (Bax) (30). Repressive MYC/MIZ1 complexes bind directly to the promoters of type I IFN regulators IRF5, IRF7, STAT1 and STAT2, resulting in the suppression of type I IFN pathway in mouse PDAC models (31). De-repression of IFN regulators allows pancreatic tumor infiltration by B cells and natural killer (NK) cells, resulting in increased survival (32). Restoration of IFN signaling might improve outcomes for PDAC patients.

\section{Discussion}

The present study showed that IFN signaling plays a role in human cancer cell lines and that the IFN and TLR3 signaling pathways may be therapeutic targets for human PDAC. We observed that IFN $\alpha$ suppressed the viability and migration of human pancreatic cancer cell lines. We also observed that 
A

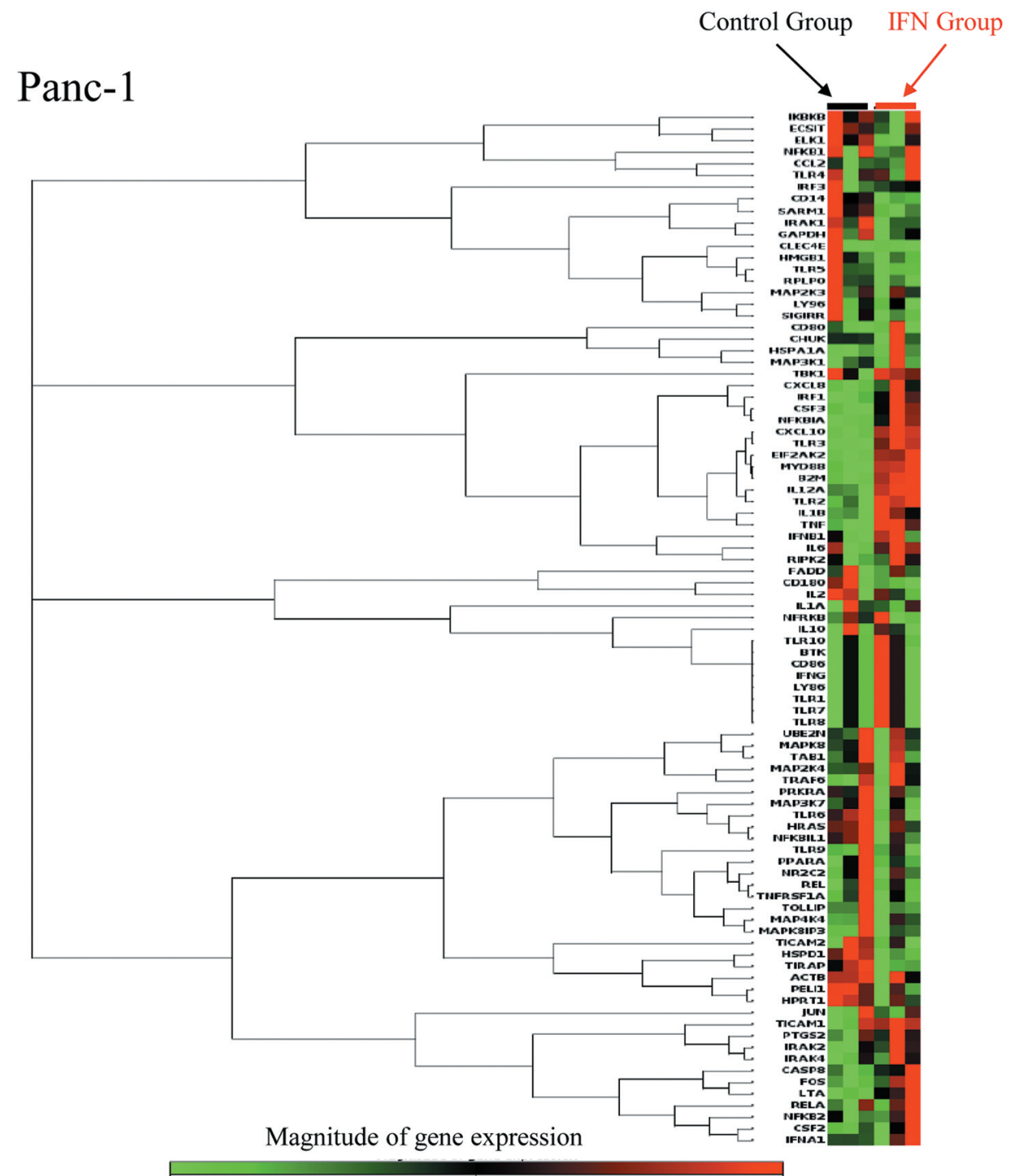

Minimum

Average

Maximum

B

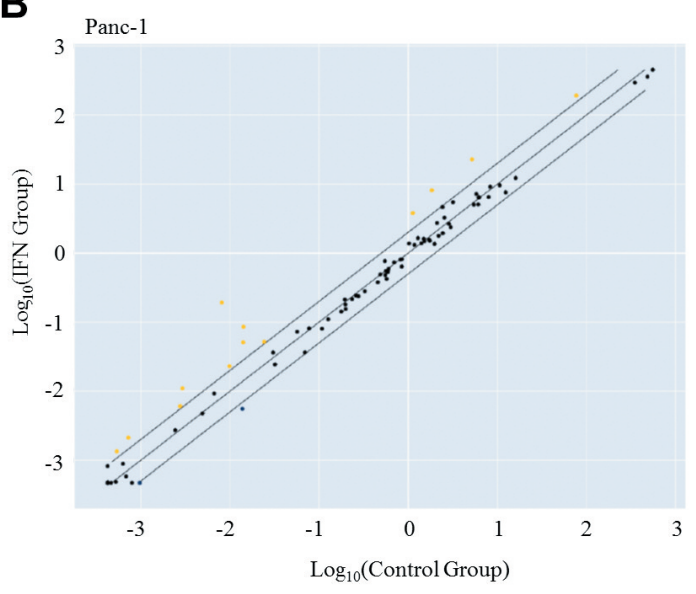

C

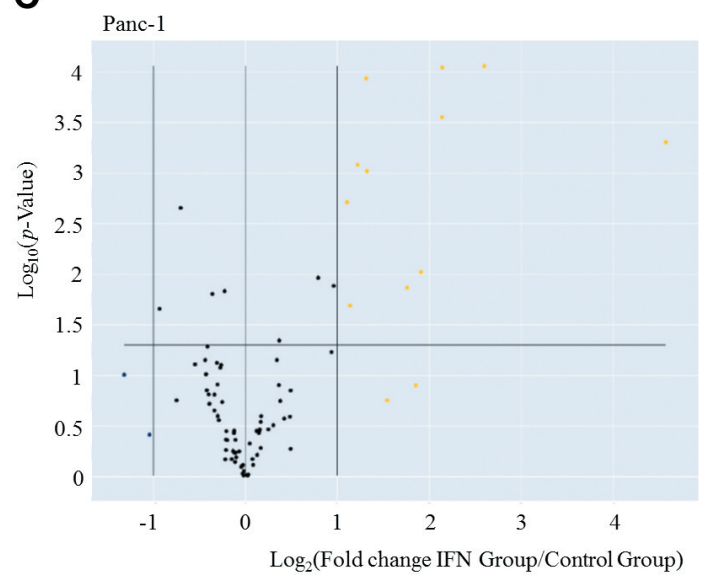

Figure 3. Continued 
D
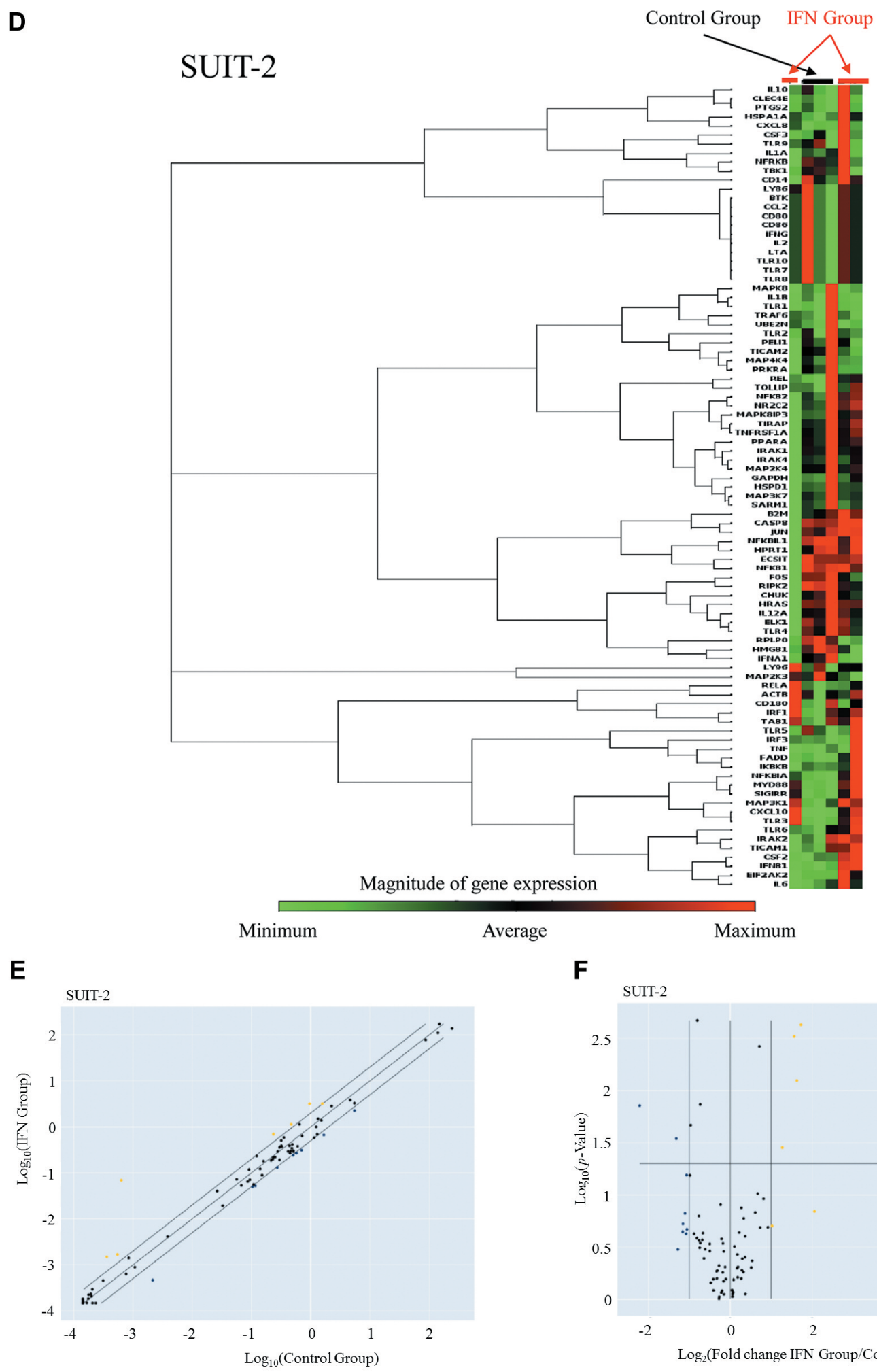

\section{Average}

Maximum

$\mathbf{F}$

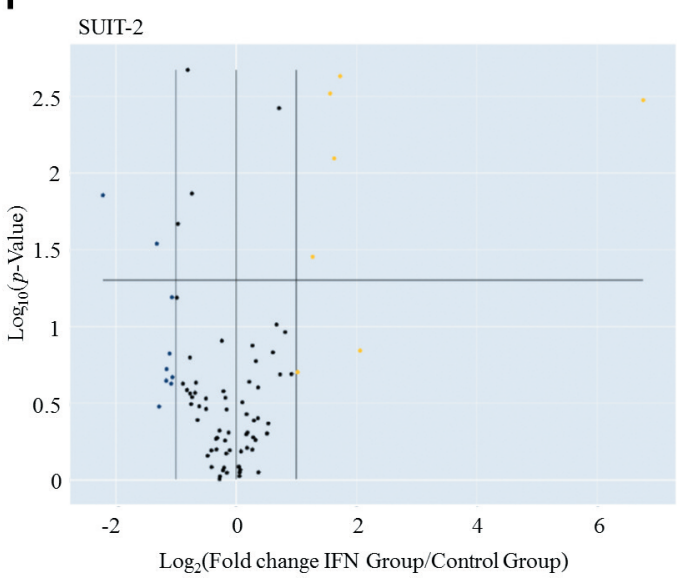

Figure 3. Gene expression analysis of toll like receptor associated genes with or without interferon alpha (IFN- $\alpha$ ) treatment of human pancreatic cancer cells. (A)-(C) Panc-1, (D)-(F) SUIT-2; (A), (D) Clustergram; (B), (E) Scatter plot comparing the normalized expressions of every gene on the PCR array between the 2 groups by plotting them against one another to quickly visualize large gene expression changes. $(C),(F)$ Volcano plot identifying significant gene expression changes by plotting the $\log 2$ of the fold changes in gene expression on the x-axis versus their statistical significance on the y-axis. Yellow circle, upregulated; blue circle, downregulated; black circle, unchanged. 

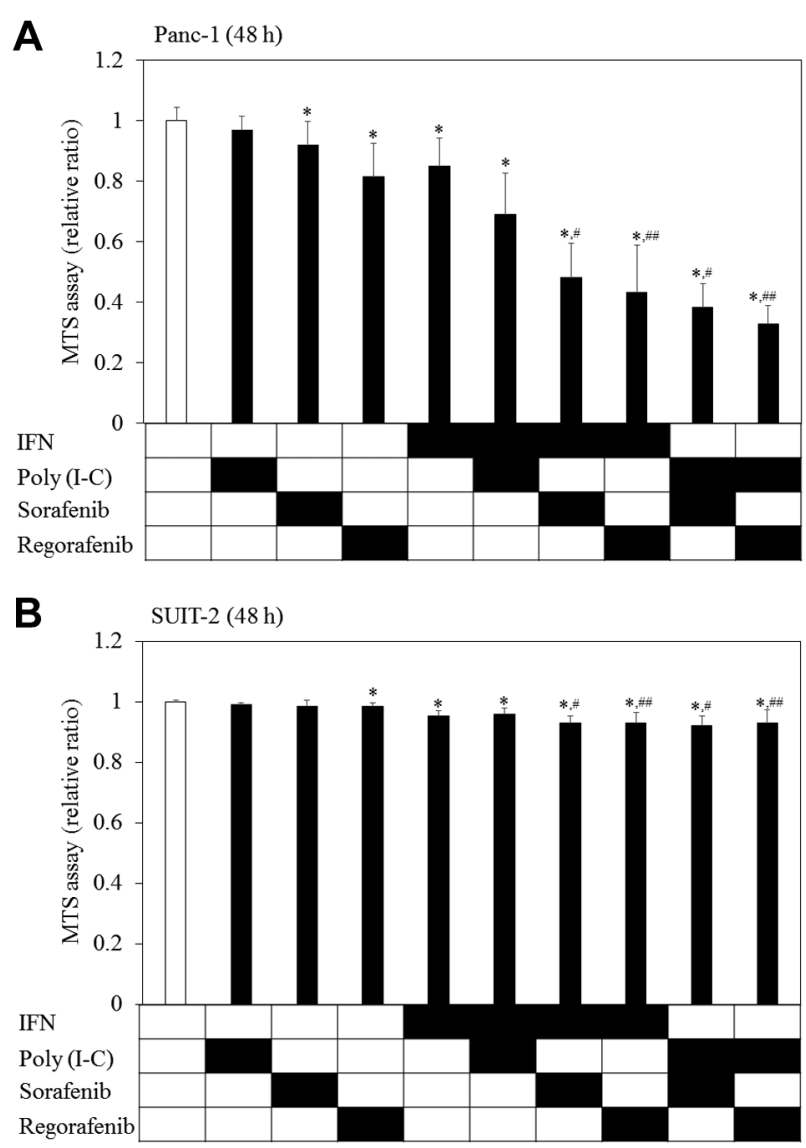

Figure 4. Additive effects of IFN $\alpha$, or poly $(I-C)$ on the effects of tyrosine kinase inhibitors on the viability of pancreatic cancer cell lines. (A) Panc1, (B) SUIT-2. Cell were treated with or without IFN $(0.05 \mu \mathrm{g} / \mathrm{ml})$, poly(IC) $(5 \mu \mathrm{g} / \mathrm{ml})$, tyrosine kinase inhibitors [sorafenib $(1 \mu \mathrm{M})$, or regorafenib $(1 \mu M)]$, or their combination for $48 h .{ }^{*} p<0.05$, compared with the control (open bar); ${ }^{\#} p<0.05$, compared with the sorafenib monotreatment; ${ }^{\#} p<0.05$, compared with the regorafenib monotreatment.

IFN $\alpha$ affects TLR signaling pathways in human pancreatic cancer cells and that TLR3 is one of the up-regulated TLRassociated genes after IFN treatment. We also observed a novel finding that, similar to IFN, poly(I-C) enhances the cytotoxicity that is induced by TKIs in human pancreatic cancer cell lines. In addition, siRNA for TLR3 attenuated the cytotoxicity that was induced by IFN $\alpha$ and regorafenib in human pancreatic cancer cells.

There is a long history of the use of IFN treatment against PDAC. Patients with PDAC exhibit deficiencies in NK cell activity and IFN production by leukocytes and these defects may contribute to the rapidly invasive and metastatic growth of PDAC (33). Previous studies have demonstrated antiproliferative effects of IFN $\alpha-2 b$ in human pancreatic cancer cells in vivo and in vitro $(14,34)$. Certain patients with advanced PDAC have exhibited clinical responses to
Table VI. Ingenuity pathway analysis between PanIN and PDAC. Top canonical pathways.

\begin{tabular}{lc}
\hline Pathways & $p$-Value \\
\hline Interferon (IFN) signaling & $p<0.05$ \\
Activation of IRF by cytosolic pattern recognition receptors & $p<0.05$ \\
Oleate biosynthesis II (animals) & $p<0.05$ \\
Antigen presentation pathway & $p<0.05$ \\
1,25-dihydroxyvitamin D3 biosynthesis & $p<0.05$ \\
\hline
\end{tabular}

Table VII. Ingenuity pathway analysis between PanIN and PDAC. Top upstream regulators.

\begin{tabular}{lcc}
\hline Regulators & $p$-Value & Predicted activation \\
\hline IFNA2 & $p<0.05$ & Activated \\
PML & $p<0.05$ & Activated \\
IFN $\alpha$ & $p<0.05$ & Activated \\
IFNL1 & $p<0.05$ & Activated \\
IRF7 & $p<0.05$ & Activated \\
\hline
\end{tabular}

IFNA2: Interferon $\alpha$-2; PML: promyelocytic leukemia; IFN $\alpha$ : interferon $\alpha$; IFNL1: interferon lambda 1; IRF7: interferon regulatory factor 7.

the treatment combination of IFN $\alpha-2 b$ and doxorubicin (34). The biochemical modulation of 5-fluorouracil (5-FU) with folic acid and IFN $\alpha$ is effective in the treatment of PDAC with moderate toxicity $(35,36)$. The greatest value of the use of IFN may be in prolonging the disease-free interval when IFN is used in combination with other treatment modalities, although these combinations have displayed significant toxicity (37-39). Natural human IFN $\alpha$ has been observed to exhibit mild or marked growth inhibition of human pancreatic cancer cells including HuP-T3, HuP-T4, MIAPaCa-2, and BxPC-3 cells (40), which supports our current results (Figure 1). Of note, we also observed that IFN $\alpha$ inhibits pancreatic cancer cell migration (Figure 2).

IFN $\alpha$ affected TLR signaling pathways in human pancreatic cancer cell lines (Tables I-IV). We also observed that IFN $\alpha$ up-regulated TLR3 expression in human pancreatic cancer cell lines. In human hepatocytes, independent pathways involving retinoic acid-inducible gene I (RIG-I), IFN induced with helicase $\mathrm{C}$ domain 1 (IFIH1/MDA5), and TLR-3 signaling comprise major pathways of host defenses that are triggered by doublestranded RNA, such as poly(I-C) (9). RIG-I and IFIH1, which are two members of the RIG-I-like receptor (RLR) family, may be able to induce growth inhibition or apoptosis of PDAC cells upon activation via RNA ligands in IFNdependent or IFN-independent approaches (41). The enhancement of RIG-I or the enhancement that results from 
IFIH1 signaling can confer potent antitumor efficacies against PDAC $(16,42-45)$, although we did not examine these two molecules.

IFN $\alpha$ partially confers its antitumor activity through its antiangiogenic activity, which results from Sp1/Sp3-mediated inhibition of VEGF gene transcription (46). The combination of IFN $\alpha$ with gemcitabine can induce apoptosis in tumorassociated endothelial cells and can reduce the growth of human pancreatic cancer cells that were orthotopically implanted in nude mice (47). In PDAC, epidermal growth factor receptor (EGFR) and the tyrosine-protein kinase Met (cMET) have been demonstrated to be overexpressed in $\sim 60 \%$ and $27-60 \%$ of cases, respectively (48). Some TKIs may be used as second-line treatments, following the use of chemotherapy. Interestingly, IFN $\alpha$ and poly(I-C) enhanced TKI-induced cytotoxicity in human pancreatic cancer cell lines (Figure 4).

In the present study, we also observed that the enhancement of TLR3 signaling confers potent antitumor efficacy against human PDAC (Figure 4), which supports the findings of a previous study (18). In general, IFN $\alpha$ induced a considerable amount of ISGs. After the knockdown of TLR3, we did not observe the attenuation of IFN $\alpha$ on cell cytotoxicity. The transcriptional regulation of TLR3 depends on IRF1 and IRF2 (49). Further studies are needed to verify these effects.

After patients with hepatitis $\mathrm{C}$ virus ( $\mathrm{HCV}$ )-related chronic liver disease underwent surveillance for hepatocellular carcinoma (HCC), some patients were diagnosed as having PDAC at a relatively early stage (50). Direct-acting antivirals against $\mathrm{HCV}$, which have recently been introduced as a treatment for $\mathrm{HCV}$, can induce rapid $\mathrm{HCV}$ clearance and changes in immune status, including serum interferon levels (51). These effects may be associated with the occurrence of PDAC. Careful attention should be paid to the pancreas during HCC surveillance (50).

PanIN includes atypical hyperplasia, papillary duct lesion with atypia, low-grade dysplasia and some cases of moderate dysplasia, and has been recognized as one of the precancerous lesions $(20,21)$. IFN signaling was shown by IPA following RNA-Seq to be a prominent different signaling pathway between PanIN and PDAC from 5 patients with PDAC, suggesting that IFN signaling pathway plays a potential role in PDAC development. In conclusion, IFN plays an essential role in PDAC development, and treatment targeting IFN and TLR3 signaling pathways will be a therapeutic option against PDAC.

In conclusion, IFN plays an essential role in human pancreatic cancer progression and treatments of PDAC, and targeting IFN and TLR3 signaling pathways may be therapeutic options against PDAC.

\section{Conflicts of Interest}

There are no conflicts of interest that could be perceived as prejudicing the impartiality of the reported research.

\section{Author's Contributions}

Conception and design: Mariko Fujisawa, Tatsuo Kanda, and Mitsuhiko Moriyama; Experiments, Data analysis and Interpretation: Mariko Fujisawa, Tatsuo Kanda, Toshikatsu Shibata, Kazumichi Kuroda, Masahiko Sugitani, and Mitsuhiko Moriyama; Article Writing: All Authors; Final approval of article: All Authors.

\section{Acknowledgements}

This work was partially supported by JSPS KAKENHI (GRANT Number JP17K09404).

\section{References}

1 Bray F, Ferlay J, Soerjomataram I, Siegel RL, Torre LA and Jemal A: Global cancer statistics 2018: GLOBOCAN estimates of incidence and mortality worldwide for 36 cancers in 185 countries. CA Cancer J Clin 68(6): 394-424, 2018. PMID: 30207593. DOI: $10.3322 / \mathrm{caac} .21492$

2 Kamisawa T, Wood LD, Itoi T and Takaori K: Pancreatic cancer. Lancet 388(10039): 73-85, 2016. PMID: 26830752. DOI: 10.1016/S0140-6736(16)00141-0

3 Shen GQ, Aleassa EM, Walsh RM and Morris-Stiff G: Nextgeneration sequencing in pancreatic cancer. Pancreas 48(6): 739748, 2019. PMID: 31206465. DOI: 10.1097/MPA.00000000 00001324

4 Midha S, Chawla S and Garg PK: Modifiable and non-modifiable risk factors for pancreatic cancer: A review. Cancer Lett 381(1): 269-277, 2016. PMID: 27461582. DOI: 10.1016/j.canlet.2016. 07.022

5 Gromisch C, Qadan M, Albuquerque Machado M, Liu K, Colson $\mathrm{Y}$ and Grinstaff MW: Pancreatic adenocarcinoma: Unconventional approaches for an unconventional disease. Cancer Res, 2020. PMID: 32220831. DOI: 10.1158/0008-5472.CAN-19-2731

6 Bazhin AV, Shevchenko I, Umansky V, Werner J and Karakhanova S: Two immune faces of pancreatic adenocarcinoma: possible implication for immunotherapy. Cancer Immunol Immunother 63(1): 59-65, 2014. PMID: 24129765. DOI: $10.1007 / \mathrm{s} 00262-013-1485-8$.

7 Ruscetti M, Morris JP 4th, Mezzadra R, Russell J, Leibold J, Romesser PB, Simon J, Kulick A, Ho YJ, Fennell M, Li J, Norgard RJ, Wilkinson JE, Alonso-Curbelo D, Sridharan R, Heller DA, de Stanchina E, Stanger BZ, Sherr CJ and Lowe SW: Senescence-induced vascular remodeling creates therapeutic vulnerabilities in pancreas cancer. Cell 181(2): 424-441.e21, 2020. PMID: 32234521. DOI: 10.1016/j.cell.2020.03.008

8 Hegde S, Krisnawan VE, Herzog BH, Zuo C, Breden MA, Knolhoff BL, Hogg GD, Tang JP, Baer JM, Mpoy C, Lee KB, Alexander KA, Rogers BE, Murphy KM, Hawkins WG, Fields RC, DeSelm CJ, Schwarz JK and DeNardo DG: Dendritic cell paucity leads to dysfunctional immune surveillance in pancreatic cancer. Cancer Cell 37(3): 289-307.e9, 2020 PMID: 32183949. DOI: $10.1016 /$ j.ccell.2020.02.008

9 Kanda T, Steele R, Ray R and Ray RB: Hepatitis C virus infection induces the beta interferon signaling pathway in immortalized human hepatocytes. J Virol 81(22): 12375-12381, 2007. PMID: 17804510. DOI: 10.1128/JVI.01695-07 
10 Booy S, Hofland LJ, Waaijers AM, Croze E, van Koetsveld PM, de Vogel L, Biermann K, and van Eijck CH: Type I interferon receptor expression in human pancreatic and periampullary cancer tissue. Pancreas 44(1): 99-105, 2015. PMID: 25072284. DOI: $10.1097 / M P A .0000000000000202$

11 Sakon M, Nagano H, Dono K, Nakamori S, Umeshita K, Yamada A, Kawata S, Imai Y, Iijima $S$ and Monden M: Combined intraarterial 5-fluorouracil and subcutaneous interferon-alpha therapy for advanced hepatocellular carcinoma with tumor thrombi in the major portal branches. Cancer 94(4): 435-442, 2002. PMID: 11900229. DOI: 10.1002/cncr.10246

12 Obi S, Yoshida H, Toune R, Unuma T, Kanda M, Sato S, Tateishi R, Teratani T, Shiina S and Omata M: Combination therapy of intraarterial 5-fluorouracil and systemic interferonalpha for advanced hepatocellular carcinoma with portal venous invasion. Cancer 106(9): 1990-1997, 2006. PMID: 16565970. DOI: $10.1002 /$ cncr.21832

13 Booy S, van Eijck CH, Dogan F, van Koetsveld PM and Hofland $\mathrm{LJ}$ : Influence of type-I Interferon receptor expression level on the response to type-I Interferons in human pancreatic cancer cells. J Cell Mol Med 18(3): 492-502, 2014. PMID: 24460759. DOI: $10.1111 /$ jcmm. 12200

14 Booy S, Hofland L and van Eijck C: Potentials of interferon therapy in the treatment of pancreatic cancer. J Interferon Cytokine Res 35(5): 327-339, 2015. PMID: 25551196. DOI: 10.1089/jir.2014.0157

15 Schmidt J, Abel U, Debus J, Harig S, Hoffmann K, Herrmann T, Bartsch D, Klein J, Mansmann U, Jäger D, Capussotti L, Kunz R and Büchler MW: Open-label, multicenter, randomized phase III trial of adjuvant chemoradiation plus interferon Alfa$2 \mathrm{~b}$ versus fluorouracil and folinic acid for patients with resected pancreatic adenocarcinoma. J Clin Oncol 30(33): 4077-4083, 2012. PMID: 23008325. DOI: 10.1200/JCO.2011.38.2960.

16 Duewell P, Steger A, Lohr H, Bourhis H, Hoelz H, Kirchleitner SV, Stieg MR, Grassmann S, Kobold S, Siveke JT, Endres S and Schnurr M: RIG-I-like helicases induce immunogenic cell death of pancreatic cancer cells and sensitize tumors toward killing by CD8(+) T cells. Cell Death Differ 21(12): 1825-1837, 2014. PMID: 25012502. DOI: 10.1038/cdd.2014.96

17 Schwartz AL, Malgor R, Dickerson E, Weeraratna AT, Slominski A, Wortsman J, Harii N, Kohn AD, Moon RT, Schwartz FL, Goetz DJ, Kohn LD and McCall KD: Phenylmethimazole decreases Toll-like receptor 3 and noncanonical Wnt5a expression in pancreatic cancer and melanoma together with tumor cell growth and migration. Clin Cancer Res 15(12): 41144122, 2009. PMID: 19470740. DOI: 10.1158/1078-0432.CCR09-0005

18 Shojaei H, Oberg HH, Juricke M, Marischen L, Kunz M, Mundhenke C, Gieseler F, Kabelitz D and Wesch D: Toll-like receptors 3 and 7 agonists enhance tumor cell lysis by human gammadelta T cells. Cancer Res 69(22): 8710-8717, 2009. PMID: 19887600. DOI: 10.1158/0008-5472.CAN-09-1602

19 Hruban RH, Takaori K, Klimstra DS, Adsay NV, AlboresSaavedra J, Biankin AV, Biankin SA, Compton C, Fukushima N, Furukawa T, Goggins M, Kato Y, Klöppel G, Longnecker DS, Lüttges J, Maitra A, Offerhaus GJ, Shimizu M and Yonezawa S: An illustrated consensus on the classification of pancreatic intraepithelial neoplasia and intraductal papillary mucinous neoplasms. Am J Surg Pathol 28(8): 977-987, 2004. PMID: 15252303. DOI: $10.1097 / 01$.pas.0000126675.59108.80
20 Vincent A, Herman J, Schulick R, Hruban RH and Goggins M: Pancreatic cancer. Lancet 378(9791): 607-620, 2011. PMID: 21620466. DOI: 10.1016/S0140-6736(10)62307-0

21 Hruban RH, Boffetta R, Hiraoka N, IacobuzioDonahue C, Kato Y, Kern SE, Klimstra DS, Klöppel G, Maitra A, Offerhaus GJA and Pitman MB: Ductal adenocarcinoma of the pancreas. In: WHO Classification of Tumours of the Digestive System. 4th Edition. Bosman FT, Carneiro F, Hruban RH Theise ND (eds.). Lyon, International Agency for Research on Cancer, pp. 281291, 2010.

22 Jiang X, Kanda T, Nakamoto S, Haga Y, Sasaki R, Nakamura M, Wu S, Mikata R and Yokosuka O: Knockdown of glucoseregulated protein 78 enhances poly(ADP-ribose) polymerase cleavage in human pancreatic cancer cells exposed to endoplasmic reticulum stress. Oncol Rep 32(22): 2343-2348, 2014. PMID: 25333575. DOI: 10.3892/or.2014.3533

23 Sasaki R, Kanda T, Fujisawa M, Matsumoto N, Masuzaki R, Ogawa M, Matsuoka S, Kuroda K and Moriyama M: Different mechanisms of action of regorafenib and lenvatinib on toll-like receptor-signaling pathways in human hepatoma cell lines. Int J Mol Sci 21(9), 2020. PMID: 32397371. DOI: 10.3390/ijms21093349

24 Okitsu K, Kanda T, Imazeki F, Yonemitsu Y, Ray RB, Chang C and Yokosuka O: Involvement of interleukin-6 and androgen receptor signaling in pancreatic cancer. Genes Cancer 1(8): 859867, 2010. PMID: 21779469. DOI: 10.1177/1947601910383417

25 Ida-Hosonuma M, Iwasaki T, Yoshikawa T, Nagata N, Sato Y, Sata T, Yoneyama M, Fujita T, Taya C, Yonekawa H and Koike $\mathrm{S}$ : The alpha/beta interferon response controls tissue tropism and pathogenicity of poliovirus. J Virol 79(7): 4460-4469, 2005. PMID: 15767446. DOI: 10.1128/JVI.79.7.4460-4469.2005

26 Overman M, Javle M, Davis RE, Vats P, Kumar-Sinha C, Xiao L, Mettu NB, Parra ER, Benson AB, Lopez CD, Munugalavadla V, Patel P, Tao L, Neelapu S and Maitra A: Randomized phase II study of the Bruton tyrosine kinase inhibitor acalabrutinib, alone or with pembrolizumab in patients with advanced pancreatic cancer. J Immunother Cancer 8(1), 2020. PMID: 32114502. DOI: $10.1136 /$ jitc-2020-000587

27 Kaowinn S, Cho IR, Moon J, Jun SW, Kim CS, Kang HY, Kim M, Koh SS and Chung YH: Pancreatic adenocarcinoma upregulated factor (PAUF) confers resistance to pancreatic cancer cells against oncolytic parvovirus $\mathrm{H}-1$ infection through IFNA receptor-mediated signaling. Biochem Biophys Res Commun 459(2): 313-318, 2015. PMID: 25727013. DOI: 10.1016/j.bbrc.2015.02.107

28 Swayden M, Alzeeb G, Masoud R, Berthois Y, Audebert S, Camon L, Hannouche L, Vachon H, Gayet O, Bigonnet M, Roques J, Silvy F, Carrier A, Dusetti N, Iovanna JL and Soubeyran P: PML hyposumoylation is responsible for the resistance of pancreatic cancer. FASEB J 33(11): 12447-12463, 2019. PMID: 31557059. DOI: 10.1096/fj.201901091R

29 Wang F, Jin R, Zou BB, Li L, Cheng FW, Luo X, Geng X and Zhang SQ: Activation of Toll-like receptor 7 regulates the expression of IFN- $\lambda 1$, p53, PTEN, VEGF, TIMP-1 and MMP-9 in pancreatic cancer cells. Mol Med Rep 13(2): 1807-1812, 2016. PMID: 26718740. DOI: 10.3892/mmr.2015.4730

30 Balabanov D, Zhao L, Zhu Z, Hunzeker ZE, Tonner HM, Ding VA, Wakefield MR, Bai Q and Fang Y: IL-29 Exhibits antitumor effect on Pan-48 pancreatic cancer cells by up-regulation of P21 and Bax. Anticancer Res 39(7): 3493-3498, 2019. PMID: 31262873. DOI: 10.21873 /anticanres. 13495 
31 Muthalagu N, Monteverde T, Raffo-Iraolagoitia X, Wiesheu R, Whyte D, Hedley A, Laing S, Kruspig B, Upstill-Goddard R, Shaw R, Neidler S, Rink C, Karim SA, Gyuraszova K, Nixon C, Clark W, Biankin AV, Carlin LM, Coffelt SB, Sansom OJ, Morton JP and Murphy DJ: Repression of the Type I interferon pathway underlies MYC \& KRAS-dependent evasion of NK \& $\mathrm{B}$ cells in pancreatic ductal adenocarcinoma. Cancer Discov, 2020. PMID: 32200350. DOI: 10.1158/2159-8290.CD-19-0620

32 Marquet RL, Schellekens H, Westbroek DL and Jeekel J: Effect of treatment with interferon and cyclophosphamide on the growth of a spontaneous liposarcoma in rats. Int J Cancer 31(2): 223-226, 1983. PMID: 6186616. DOI: 10.1002/ijc.2910310215

33 Funa K, Nilsson B, Jacobsson G and Alm GV: Decreased natural killer cell activity and interferon production by leucocytes in patients with adenocarcinoma of the pancreas. Br J Cancer 50(2): 231-233, 1984. PMID: 6466540. DOI: 10.1038/bjc.1984.168

34 Welander CE: Overview of preclinical and clinical studies of interferon alfa-2b in combination with cytotoxic drugs. Invest New Drugs 5: S47-S59, 1987. PMID: 3298133. DOI: $10.1007 / \mathrm{BF} 00207263$

35 Knuth A, Bernhard H, Klein O and Meyer zum Büschenfelde $\mathrm{KH}$ : Combination fluorouracil, folinic acid, and interferon alfa2a: an active regimen in advanced pancreatic carcinoma. Semin Oncol 19(2 Suppl 3): 211-214, 1992. PMID: 1557650.

36 Bernhard H, Jäger-Arand E, Bernhard G, Heike M, Klein O, Riemann JF, Meyer zum Büschenfelde KH, Dippold W and Knuth A: Treatment of advanced pancreatic cancer with 5fluorouracil, folinic acid and interferon alpha-2A: results of a phase II trial. Br J Cancer 71(1): 102-105, 1995. PMID: 7819023. DOI: $10.1038 /$ bjc. 1995.20

37 Pazdur R, Ajani JJ, Abbruzzese JL, Belt RJ, Dakhil SR, Dubovsky D, Graham S, Pilat S, Winn R and Levin B: Phase II evaluation of fluorouracil and recombinant alpha-2a-interferon in previously untreated patients with pancreatic adenocarcinoma. Cancer $70(8)$ : 2073-2076, 1992. PMID: 1394037. DOI: 10.1002/10970142(19921015)70:8<2073::aid-cncr2820700810>3.0.co;2-a

38 Hansen RM and Borden EC: Current status of interferons in the treatment of cancer. Oncology (Williston Park) 6(11): 19-24, 1992. PMID: 1280153.

39 John WJ and Flett MQ: Continuous venous infusion 5fluorouracil and interferon-alpha in pancreatic carcinoma. Am J Clin Oncol 21(2): 147-150, 1998. PMID: 9537201. DOI: 10.1097/00000421-199804000-00011

40 Matsubara N, Fuchimoto S and Orita K: Antiproliferative effects of natural human tumor necrosis factor-alpha, interferon-alpha, and interferon-gamma on human pancreatic carcinoma cell lines. Int J Pancreatol 8(3): 235-243, 1991. PMID: 1904907. DOI: 10.1007/BF02924542

$41 \mathrm{Wu}$ Y, Wu X, Wu L, Wang X and Liu Z: The anticancer functions of RIG-I-like receptors, RIG-I and MDA5, and their applications in cancer therapy. Transl Res 190: 51-60, 2017. PMID: 28917654. DOI: 10.1016/j.trsl.2017.08.004

42 Ellermeier J, Wei J, Duewell P, Hoves S, Stieg MR, Adunka T, Noerenberg D, Anders HJ, Mayr D, Poeck H, Hartmann G, Endres $S$ and Schnurr M: Therapeutic efficacy of bifunctional siRNA combining TGF- $\beta 1$ silencing with RIG-I activation in pancreatic cancer. Cancer Res 73(6): 1709-1720, 2013. PMID: 23338611. DOI: 10.1158/0008-5472.CAN-11-3850
43 Meng G, Xia M, Xu C, Yuan D, Schnurr M and Wei J: Multifunctional antitumor molecule 5'-triphosphate siRNA combining glutaminase silencing and RIG-I activation. Int $\mathrm{J}$ Cancer 134(8): 1958-1971, 2014. PMID: 23921958. DOI: $10.1002 / \mathrm{ijc} .28416$

44 Duewell P, Beller E, Kirchleitner SV, Adunka T, Bourhis H, Siveke J, Mayr D, Kobold S, Endres S and Schnurr M: Targeted activation of melanoma differentiation-associated protein 5 (MDA5) for immunotherapy of pancreatic carcinoma. Oncoimmunology 4(10): e1029698, 2015. PMID: 26504669. DOI: $10.1080 / 2162402 X .2015 .1029698$

45 Das M, Shen L, Liu Q, Goodwin TJ and Huang L: Nanoparticle delivery of RIG-I agonist enables effective and safe adjuvant therapy in pancreatic cancer. Mol Ther 27(3): 507-517, 2019. PMID: 30545600. DOI: 10.1016/j.ymthe.2018.11.012

46 von Marschall Z, Scholz A, Cramer T, Schäfer G, Schirner M, Oberg K, Wiedenmann B, Höcker M and Rosewicz S: Effects of interferon alpha on vascular endothelial growth factor gene transcription and tumor angiogenesis. J Natl Cancer Inst 95(6): 437-448, 2003. PMID: 12644537. DOI: 10.1093/jnci/95.6.437

47 Solorzano CC, Hwang R, Baker CH, Bucana CD, Pisters PW, Evans DB, Killion JJ and Fidler IJ: Administration of optimal biological dose and schedule of interferon alpha combined with gemcitabine induces apoptosis in tumor-associated endothelial cells and reduces growth of human pancreatic carcinoma implanted orthotopically in nude mice. Clin Cancer Res 9(5): 1858-1867, 2003. PMID: 12738744.

48 Madamsetty VS, Pal K, Dutta SK, Wang E, Thompson JR, Banerjee RK, Caulfield TR, Mody K, Yen Y, Mukhopadhyay D and Huang HS: Design and evaluation of PEGylated liposomal formulation of a novel multikinase inhibitor for enhanced chemosensitivity and inhibition of metastatic pancreatic ductal adenocarcinoma. Bioconjug Chem 30(10): 2703-2713, 2019 PMID: 31584260. DOI: 10.1021/acs.bioconjchem.9b00632

49 Sun L, Jiang Z, Acosta-Rodriguez VA, Berger M, Du X, Choi JH, Wang J, Wang KW, Kilaru GK, Mohawk JA, Quan J, Scott L, Hildebrand S, Li X, Tang M, Zhan X, Murray AR, La Vine D, Moresco EMY, Takahashi JS and Beutler B: HCFC2 is needed for IRF1- and IRF2-dependent Tlr3 transcription and for survival during viral infections. J Exp Med 214(11): 3263-3277, 2017. PMID: 28970238. DOI: 10.1084/jem.20161630

50 Kumagi T, Terao T, Yokota T, Azemoto N, Kuroda T, Imamura Y, Uesugi K, Kisaka Y, Tanaka Y, Shibata N, Koizumi M, Ohno Y, Yukimoto A, Tange K, Nishiyama M, Kanemitsu K, Miyake T, Miyata $\mathrm{H}$, Ishii $\mathrm{H}$ and Hiasa $\mathrm{Y}$; Ehime Pancreato-Cholangiology (EPOCH) Study Group: Early detection of pancreatic cancer in patients with chronic liver disease under hepatocellular carcinoma surveillance. Mayo Clin Proc 94(10): 2004-2010, 2019. PMID: 31262521. DOI: 10.1016/j.mayocp.2018.12.034

51 Sasaki R, Meyer K, Moriyama M, Kato N, Yokosuka O, Ray RB, Aurora R, Ray R and Kanda T: Rapid hepatitis C virus clearance by antivirals correlates with immune status of infected patients. J Med Virol 91(3): 411-418, 2019. PMID: 30192392. DOI: $10.1002 /$ jmv. 25310

Received June 4, 2020

Revised June 24, 2020

Accepted June 25, 2020 